\title{
Bilecik İlindeki Şehirleşmenin Taşkın Riski Üzerindeki Etkilerinin Araştırılması
}

\section{Investigation of Effects of Urbanization on Flood Risk in Bilecik Province}

\begin{abstract}
Y1ldırım Bayazit $^{1 *}$
Geliş / Received: 09/02/2021

Revize / Revised: 29/05/2021

Kabul / Accepted: 16/06/2021

ÖZ

Taşkınlar, son yıllarda doğal dengenin giderek bozulması sonucu, şiddetini ve yıkıcılığını arttırmakta ve daha sık meydana gelmektedir. Taşkınların yaşanmasındaki en önemli nedenlerden biri şehirleşmeyle meydana gelen arazi kullanımındaki değişimlerdir. Bu çalışmada, ilk olarak uzaktan algılama ile şehirleşmedeki değişimin bulunması hedeflenmiştir. Daha sonra, coğrafi bilgi sistemlerinden yararlanarak şehirleşmedeki bu değişimin taşkın riski üzerindeki etkisinin ortaya konulması hedeflenmiştir. Çalışmada, Bilecik ilinin 2000 ve 2018 yıllarına ait CORINE arazi kullanımı haritaları kullanılarak arazi sınıflarındaki değişim incelenmiştir. Bölgedeki taşkın riskini etkileyebilecek yağış, eğim, yükseklik ve arazi kullanımı ve akarsulara uzaklık gibi parametrelerin modellemeye eklenmesiyle birlikte Çok Kriterli Karar Verme Analiziyle taşkın risk haritası modellemeleri yapılmıştır. Yapılan çalışma sonucunda, 2000 yılından 2018yılına kadar bölgenin arazi yapısı değişiminin taşkın riski üzerindeki etkisi ortaya konmuştur. 2000 yılında taşkın riski altında olan alan 12250 ha iken 2018 yılında bu alan 13547 ha olmuştur. $\mathrm{Bu}$ durum şehirleşmenin taşkın riski üzerindeki negatif etkisini açık bir şekilde ortaya koymaktadır.
\end{abstract}

Anahtar Kelimeler-Taşkın Riski, Uzaktan Algılama, Coğrafi Bilgi Sistemleri, Bilecik

\begin{abstract}
In recent years, as a result of the gradual deterioration of the natural balance, floods increase their severity and destructiveness and occur more frequently. One of the most important reasons for floods is the changes in the land caused by urbanization. In this study, firstly, it is aimed to find the change in urbanization with remote sensing. Then it is aimed to reveal the effect of this change in urbanization on flood risk by using geographical information systems. In the study, the change in land classes was examined by using the CORINE land use maps of Bilecik province for the years 2000 and 2018. With the addition of parameters, such as precipitation, slope, elevation and land use, and distance to rivers, which may affect the flood risk in the region, flood risk map modeling has been carried out with Multi-Criteria Decision Making Analysis. As a result of the study, the effect of the land structure change of the region on the flood risk from 2000 to 2018 has been revealed. While the area under flood risk was 12,250 ha in 2000 , this area was 13,547 ha in 2018 . This situation clearly reveals the negative effect of urbanization on flood risk.
\end{abstract}

Keywords- Flood Risk, Remote Sensing, Geographical Information Systems, Bilecik

1*Sorumlu yazar iletişim: yildirim.bayazit@bilecik.edu.tr (https://orcid.org/0000-0002-8699-4741)

İnşaat Mühendisliği Bölümü, Bilecik Şeyh Edebali Üniversitesi, Mühendislik Fakültesi, Bilecik, Türkiye 


\section{GİRİ̧}

Taşkınlar özellikle son otuz yılda büyük bir artış göstermiştir. Bunun başlıca nedenleri arasında insanlığın doğurduğu iklim değişikliği ve doğal arazi örtüsünün şehirleşme için bozulması gösterilmektedir [1]. Taşkınların en çok etkilediği alanlar ile kentsel bölgeler arasında karşılıklı bir etkileşim olduğu bilinmektedir. Bu durum şehirleşmenin getirdiği arazi değişiminin taşkınların meydana gelmesindeki en önemli faktörlerden birisi olduğunu ortaya koymaktadır. Taşkınlar tüm dünyada olduğu gibi ülkemizde de önemli bir risk faktörüdür. Ülkemizdeki taşkın istatistiklerine göre 1975-2015 yılları arasında toplam 1.209 taşkın meydana gelmiştir. Bu taşkınlarda 893.933 ha alan su altında kalmış 720 can kaybı yaşanmıştır [2].

Taşkın yayılımları ve risklerini belirlemek için yapılan çalışmalarda, Uzaktan Algılama (UA) ve Coğrafi Bilgi Sistemleri (CBS) son yıllarda en çok kullanılan yöntemlerdir. Şehirleşme ve doğal arazi değişiminin ortaya konması için UA yöntemleri kullanılmaktadır. Uydu teknolojilerinin gelişmesiyle şehirlerin geçmiş yıllardan bugüne uydu görüntüleri temin edilebilmektedir. $\mathrm{Bu}$ uydu görüntülerinin analiziyle arazi değişimi ortaya konularak taşkınlara etkisi değerlendirilebilmektedir. Bu konuda son yıllarda birçok çalışma ortaya konmuştur; Park ve Lee yaptıkları çalışmada, kentsel planlamada sel hasarını en aza indirmek için doğal toprak yapısının korunması gerektiğini vurgulamışlardır [3]. Shanableh ve ark. kentleşmenin akış, yerel sel ve yağmursuyu hasadı üzerindeki etkisini uydu görüntülerini kullanarak uzaktan algılamayla incelemiştir [4]. Barasa ve Perera, Kenya'da Sosiani Nehrinde meydana gelen ani taşkınların şehirleşme ve ormansızlaşma ile ilişkisini analiz etmiştir [5]. Du ve ark. 1980, 2005 ve 2015 yıllarının uydu görüntülerini inceleyerek arazi değişimlerindeki kentleşme faktörünün taşkınlara etkisini araştırmışlardır [6]. Veerbeek yaptı̆̆ı doktora tezinde şehirleşmedeki büyümenin gelecekteki taşkın riskleri üzerindeki etkilerini birçok şehri ele alarak karşılaştırmalı olarak incelemiştir [7]. Bir başka doktora tezinde kentleşme ve çevresel etkilerin uzaktan algılanması üzerine çalışılıışıtır [8].Bir diğer yöntem olarak öne çıkan CBS, hidrolojik analizler ve taşkın risk haritalarının oluşturulması gibi analizleri ortaya koyar. CBS, bir veri tabanı altında verileri saklayabilen, konumsal analize dayanan görsel sonuçlar verebilen bir analiz metodudur. Son yıllarda taşkın yönetimi ve su kaynakları planlamaları gibi alanlarda sıklıkla kullanılmaktadır; Özkan ve Tarhan, CBS kullanarak İzmir'de sel tehlikesinin saptanması üzerine çalışmışlardır [9]. Ayrıca bazı çalı̧malarda, CBS tabanlı bir model oluşturularak kentsel su baskını simülasyonları gerçekleştirilmiştir [10, 11]. Bu çalışmada da kullanılan CBS tabanlı çok kriterli analiz yöntemi kullanılarak kentsel taşkın duyarlılık analizleri yapılmış̧ır [12, 13]. Hidrolojik ve hidrolik analizlerin CBS kullanılarak birlikte ele alındığı çalışmalar da yapılmıştır[14, 15].

Bu çalışmada, Bilecik ilinin 2000 ve 2018 yllarına ait Coordination of Information on the EnvironmentÇevresel Bilginin Koordinasyonu (CORINE) arazi kullanımı haritaları analiz edilerek şehirleşme sonucu taşkın risk haritası modellemelerinin yapılması amaçlanmıştır. Yağış, eğim, yükseklik, arazi kullanımı ve akarsulara uzaklık gibi parametrelerin Çok Kriterli Karar Verme yöntemiyle ArcGIS 10.5 yazılımında analizi yapılarak Bilecik iline ait taşkın risk haritalarının oluşturulması hedeflenmiştir.

\section{II. ÇALIȘMA ALANI}

Çalışma alanı olarak Türkiye'nin Güney Doğu Marmara Bölgesinde yer alan Bilecik il sınırları seçilmiştir. Bilecik'te geçmişten günümüze birçok taşkın meydana gelmiştir. Bu taşkınların birçoğu il merkezi ve ilçelerinde meydana gelmektedir. Şekil 1(a)'da Bozüyük ilçesinde 07.04.2021 tarihinde meydana gelen taşkında bazı ev ve bahçelerin sular altında kaldığı görülmektedir. Şekil 1(b)'de 19.08.2018 tarihinde Bilecik il merkezinde bazı evlerin ve iş yerlerinin sular altında kaldığı gözükmektedir. Şekil 1(c)'de görülen taşkın görüntüsünde ise Bilecik'in Osmaneli ilçesinden geçen Göksu Nehri'nin taşması sonucu 200 dönüm tarım alanının sular altında kaldığı bilinmektedir. Bilecik ilinin toplam nüfusu 218.717'dir. Özellikle taşkınların yaşandığı bölgelerin kent merkezi, Bozüyük ve Osmaneli ilçeleri gibi yoğun nüfus ve kentleşmenin olduğu bölgeler olduğu bilinmektedir. Bu nedenle çalışmada Bilecik ili ele alınmıştır. 


\begin{tabular}{|c|c|c|}
\hline & $\begin{array}{l}\text { BŞEÜ Fen Bilimleri Dergisi } \\
8(1), 217-227,2021\end{array}$ & $\begin{array}{r}\text { BSEU Journal of Science } \\
\text { https://doi.org/10.35193/bseufbd.877539 }\end{array}$ \\
\hline $\begin{array}{l}\text { BulECECKSEYHEDEBAL } \\
\text { ONIVERSITESI }\end{array}$ & & 2458-7575 (https://dergipark.org.tr/tr/pub/bseufbd) \\
\hline
\end{tabular}

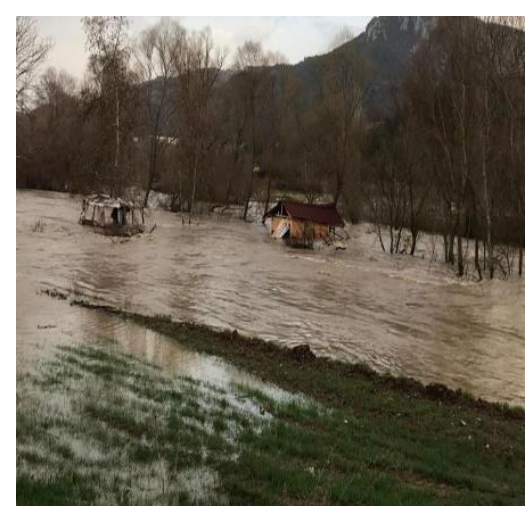

(a)

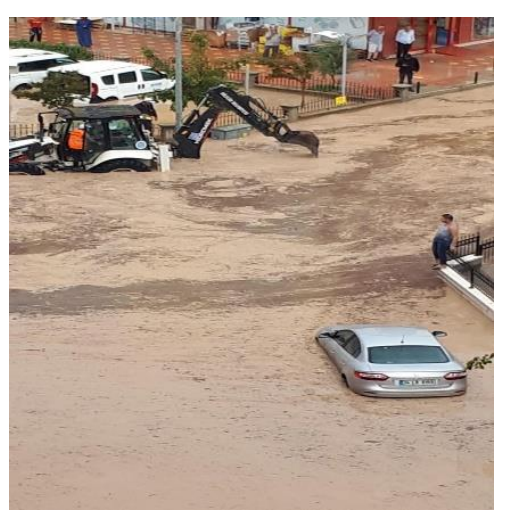

(b)

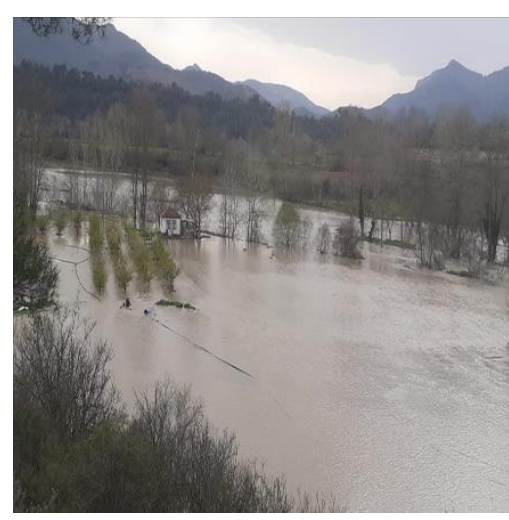

(c)

Şekil 1. Bilecik’te yaşanan bazı taşkınlardan görüntüler

Bilecik, Marmara, Karadeniz, İç Anadolu ve Ege Bölgelerinin kesişimi olan bir coğrafyada bulunur. Bilecik ilinin yüzölçümü 4230,48 km²'dir. Çalışma alanı Universal Transverse Mercator (UTM) koordinat sistemine göre metre biriminde 464908,178 D, 4788110,514 K ile 503524,193 D, 4787951,764 K enlem ve boylamları arasında yer almaktadır (Şekil 2) Bilecik ilinin ortalama aylık sıcaklık değerleri 2,6-22 ${ }^{\circ} \mathrm{C}$ aralığında değişmektedir. Bölgeye düşen yıllık toplam yağış ortalaması ise 457,47 mm'dir. Bölgenin en önemli su kaynağ Sakarya Nehri'dir.
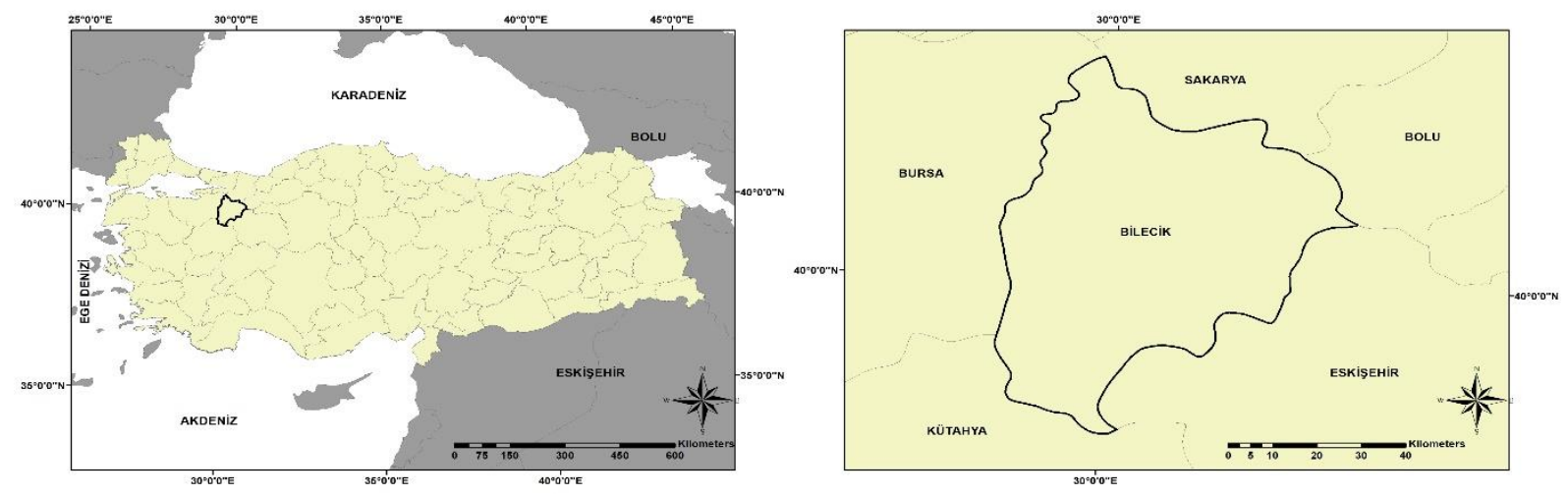

Şekil 2. Bilecik ilinin Türkiye'deki konumu

\section{VERİ VE YÖNTEM}

Çalışmada, Bilecik ilinin taşkın risk haritasını elde edebilmek için birçok veri ve yöntemden faydalanılmıştır. Bu çalışmadaki analizlerde kullanılan veriler ve yöntemler aşağıda başlıklar halinde verilerek açıklanmıştır.

\section{A. Veri}

1) Yağ lş: Yağış taşkın risk analizlerinin en önemli verilerinden biridir. Bu veriler günlük, aylık ve yıllık kayıtlar şeklinde elde edilebilmektedir. Bu çalışmada Bilecik ilindeki 5 adet meteoroloji gözlem istasyonu yağış verileri aylık olarak Meteoroloji Genel Müdürlüğü’nden temin edilmiştir. Çalışmada kullanılan meteoroloji istasyonlarının bilgileri Tablo 1'de verilmiştir. 
Tablo 1. Çalışmada kullanılan yağışölçer istasyonların özellikleri

\begin{tabular}{|c|c|c|c|c|c|c|}
\hline $\begin{array}{c}\text { İstasyon } \\
\text { No }\end{array}$ & $\begin{array}{c}\text { İstasyon } \\
\text { Adı }\end{array}$ & $\begin{array}{c}\text { Koordinatlar } \\
\text { (UTM) }\end{array}$ & $\begin{array}{c}\text { Zaman Aralığı } \\
\text { (yıl) }\end{array}$ & $\begin{array}{c}\text { Veri } \\
\text { Tipi }\end{array}$ & $\begin{array}{c}\text { Standart } \\
\text { Sapma }\end{array}$ & $\begin{array}{c}\text { Yıllık Ortalama Yağı̧̧ } \\
\text { (mm) }\end{array}$ \\
\hline 2707 & Yenipazar & $\begin{array}{c}703342.269 \mathrm{D} \\
4863693.667 \mathrm{~K}\end{array}$ & $1991-1996$ & Aylık & 23,77 & 442,4 \\
\hline 2980 & Söğüt & $\begin{array}{c}674109.575 \mathrm{D} \\
4846118.783 \mathrm{~K}\end{array}$ & $1991-1995$ & Aylık & 34,59 & 560,1 \\
\hline 3149 & Pazaryeri & $\begin{array}{c}650822.029 \mathrm{D} \\
4844986.005 \mathrm{~K}\end{array}$ & $1991-1998$ & Aylık & 27,43 & 432,1 \\
\hline 17120 & Bilecik & $\begin{array}{c}657213.270 \mathrm{D} \\
4861048.726 \mathrm{~K}\end{array}$ & $1979-2011$ & Aylık & 30,65 & 464,4 \\
\hline 17702 & Bozüyük & $\begin{array}{c}662382.368 \mathrm{D} \\
4834373.556 \mathrm{~K}\end{array}$ & $1979-2011$ & Aylık & 33,20 & 505,4 \\
\hline
\end{tabular}

Bilecik ilindeki7 adet yağış ölçen meteoroloji istasyonundaki aylık yağış verileri bir Coğrafi Bilgi Sistemi yazılımı olan ArcGIS 10.5'in veri tabanına aktarılmıştır. ArcGIS programına aktarılan yağış verileri Inverse Distance Weighting - Uzaklığın Tersi ile Ağırlıklandırma (IDW) konumsal enterpolasyon yöntemiyle Bilecik ilinin yağış dağılım haritası oluşturulmuştur (Şekil 3). IDW, değerleri bilinen dağınık nokta kümesinin çok değişkenli enterpolasyonu için kullanılan bir yöntemdir. Değeri bilinen noktaların ağırlıklı ortalaması kullanılarak bilinmeyen noktaların değer tahminlemesi yapılır [16-18].

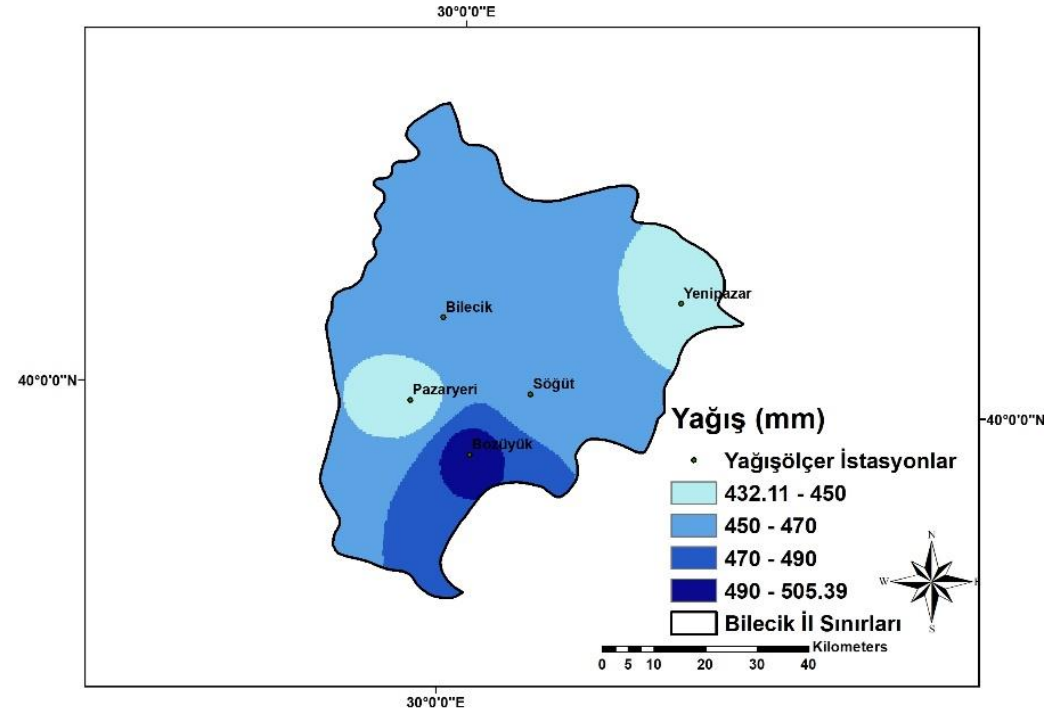

Şekil 3. Bilecik ili yağış haritası

2) Ĕ̆gim: Arazinin eğimi taşkının oluşmasında önemli bir etkiye sahip olan jeomorfolojik özelliklerden birisidir. Eğimin fazla olduğu arazide, düşen yağışın sızma eğilimi daha az olacağından akışa geçme oranı artar. Aynı zamanda akış hızı ve toplanma süresi de artar. Dolayısıyla akışa geçen hacmin fazla olduğu yerlerde taşkın riski de büyüyecektir. Bu nedenle çalışma alanının eğim haritalarının oluşturulması büyük önem arz etmektedir. Çalışma alanına ait sayısal yükseklik modelinden (SYM) yararlanılarak ArcGIS 10.5'te yüzey analizleri yöntemi kullanılarak eğim haritası oluşturulmuştur (Şekil 4). 


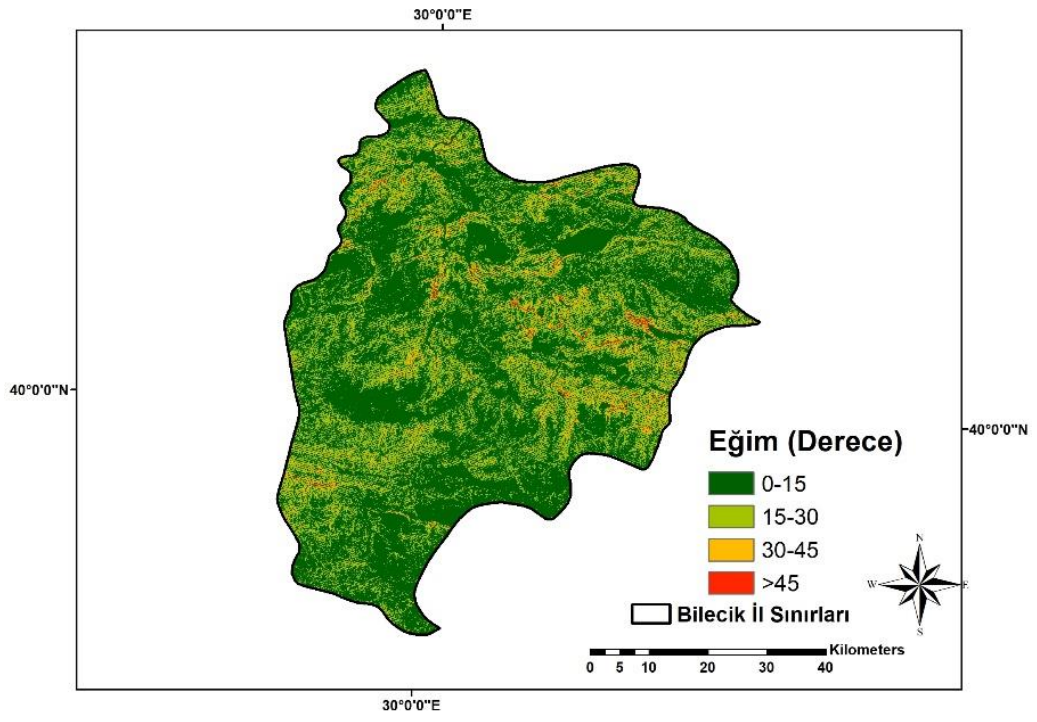

Şekil 4. Bilecik ili eğim haritası

3) Yükseklik: Taşkın risk analizlerinde bölgenin topografik özellikleri arasında yükseklik önemli bir yer tutmaktadır. Taşkınlar arazi kotlarının düşük olduğu yerlerde daha fazla meydana gelirler. Bir bölgeye düşen yağgş, akış yollarıyla birlikte en düşük kota gitme eğilimindedir [19]. Aynı zamanda yükseklikler yağış türünü de etkilemektedir. Bu durum sızma ve akışa da etki eder. Bu nedenle taşkın risk analizlerinde yükseklik faktörü belirlenmesi önemlidir. Bu çalışmada SYM'nin yeniden sınıflandırılmasıyla Bilecik ilinin yükseklik haritası elde edilmiştir (Şekil 5).

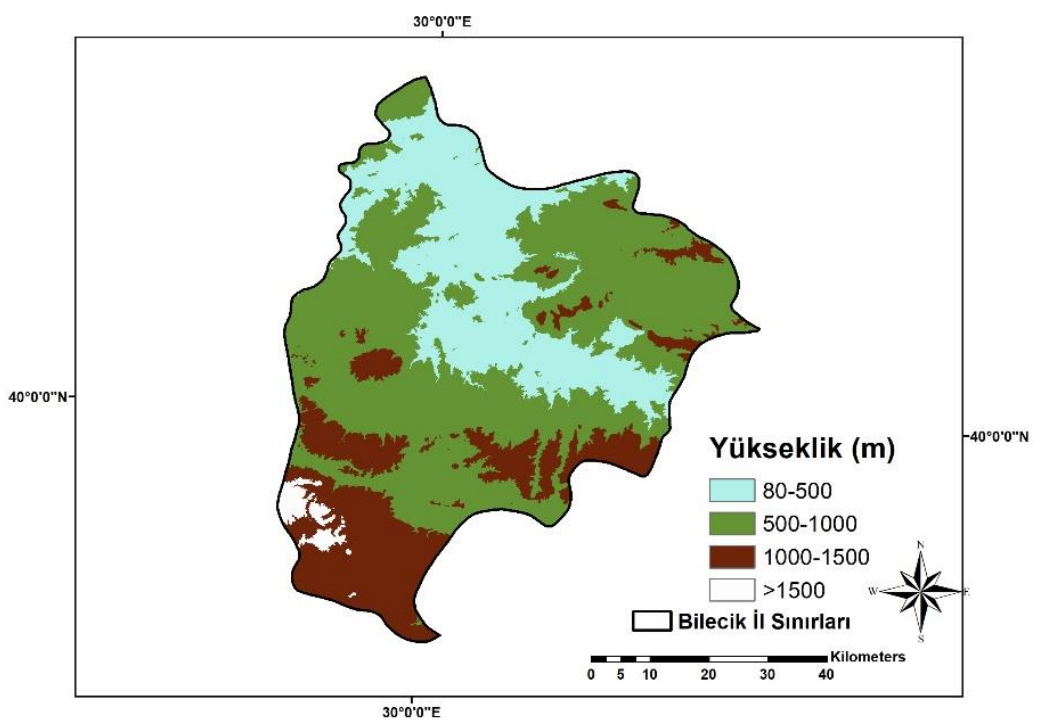

Şekil 5. Bilecik ili yükseklik haritası

4) Arazi Kullanımı: Son yıllarda hızla gelişen uydu teknolojileriyle birlikte uzaktan algılama yöntemlerinin kullanımı büyük artış göstermiştir. Özellikle taşkın risk çalışmalarında arazi kullanımının taşkın riski üzerindeki etkileri uydu görüntülerinin uzaktan algılama yöntemleriyle incelenmesi sonucu ele alınmaktadır. Günümüzde uydu görüntüleri birçok platformdan ücretsiz olarak erişilebilir durumdadır. Arazi kullanımı için kullanılabilecek uydu görüntülerinin yanı sıra CORINE resmi web sitesinden Avrupa ülkeleri ve Türkiye'nin arazi kullanımı haritaları 100 m konumsal çözünürlükte elde edilebilmektedir. Bu çalışma kapsamında Bilecik ilindeki şehirleşmenin taşkın riski üzerindeki etkisini inceleyebilmek için 2000 ve 2018 yıllarına ait arazi kullanımı haritaları CORINE web sitesinden elde edilerek analiz edilmiştir [20]. Bölgenin arazi kullanımı, CORINE arazi 


\begin{tabular}{|c|c|c|}
\hline & $\begin{array}{l}\text { BŞEÜ Fen Bilimleri Dergisi } \\
8(1), 217-227,2021\end{array}$ & $\begin{array}{r}\text { BSEU Journal of Science } \\
\text { https://doi.org/10.35193/bseufbd.877539 }\end{array}$ \\
\hline $\begin{array}{l}\text { BulECECKSEYHEDEBAL } \\
\text { ONIVERSITESI }\end{array}$ & & 2458-7575 (https://dergipark.org.tr/tr/pub/bseufbd) \\
\hline
\end{tabular}

sınıflandırmasına göre yeniden sınıflandırılarak çalışma alanına ait 2000 ve 2018 yıllarının arazi kullanımı haritaları üretilmiştir (Şekil 7). 2000 yılında Bilecik ilinde yerleşim yeri büyüklüğünün göstergesi olan yapay yüzeylerin 4.568 ha alan kapladığı görülmüștür. Bunun yanı sıra bölgenin diğer arazi kullanımları 145.964 ha tarım alanı, 272.208 ha orman ve 308 ha ise su yüzeyleri olarak hesaplanmıştır. 2018 yılında ise yapay yüzeylerin 6.866 ha alan kapladığ1 görülmüştür. Bu durum bölgede şehirleşmenin \% $\%, 43$ artış gösterdiğini ortaya koymaktadır. 2018 yılı arazi kullanımına göre bölgenin geri kalanını 171.628 ha ile tarım alanları, 243.845 ha ile Orman alanları 709 ha ile ise su yüzeylerinin oluşturduğu görülmüştür (Şekil 6). 2000 ve 2018 yılları arasında arazi kullanımının değişimi bölgede şehirleşmenin hızlı bir şekilde arttığını göstermektedir. Şehirleşmenin artmasıyla düşen yağışın sızamadan doğrudan akışa geçeceği alanlar artmıştır. Bu durum son yıllarda bölgede artan taşkın olaylarını açıklayabilmektedir. Çalışmada incelenen havzaların 2000 ve 2018 yıllarındaki arazi kullanım haritaları Şekil 7'de verilmiştir.

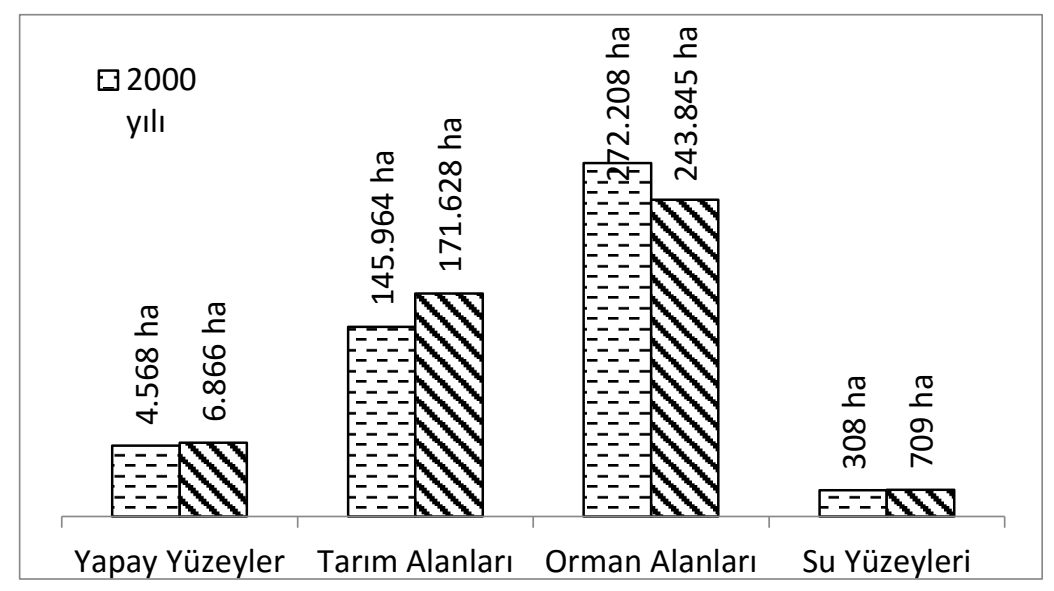

Şekil 6. 2000 ve 2018 yılları arasında arazi kullanımının değişimi
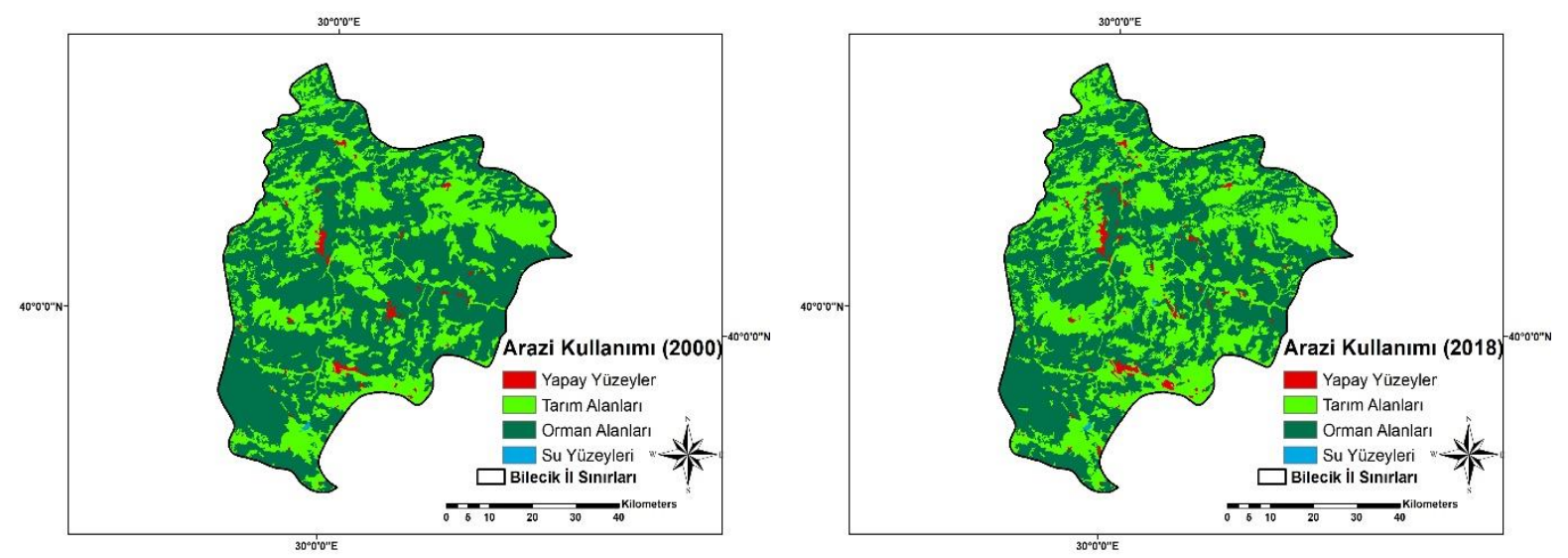

Şekil 7. Bilecik ilinin 2000 ve 2018 yıllarına ait arazi kullanım haritaları

5) Akarsulara Uzaklık: Akarsulara uzaklık taşkın riski açısından bir diğer önemli faktördür. Akarsu yatağından uzaklık arttıkça taşkın riski düşmektedir. Bunun yanı sıra akarsuyun akış sırasına göre derecesi de akarsuyun taşıdığı akış debisi açısından bir diğer önemli faktördür. Çalışmada Bilecik il sınırlarındaki akarsular Strahler akış sırası yöntemine göre derecelendirilerek taşıdığı akış debisi büyüklüklerine göre sınıflandırılmıştır (Şekil 8). Çalışmada incelenmek istenen taşkın risk analizlerinde akarsulara uzaklık kriteri aynı zamanda akarsuyun dereceleriyle birlikte ele alınmıştır. 


\begin{tabular}{|c|c|c|}
\hline & $\begin{array}{l}\text { BŞEÜ Fen Bilimleri Dergisi } \\
8(1), 217-227,2021\end{array}$ & $\begin{array}{r}\text { BSEU Journal of Science } \\
\text { https://doi.org/10.35193/bseufbd } 877539\end{array}$ \\
\hline $\begin{array}{l}\text { BiliecEISSEYHEDEBALI } \\
\text { ONIVERSITESI }\end{array}$ & & 2458-7575 (https://dergipark.org.tr/tr/pub/bseufbd) \\
\hline
\end{tabular}

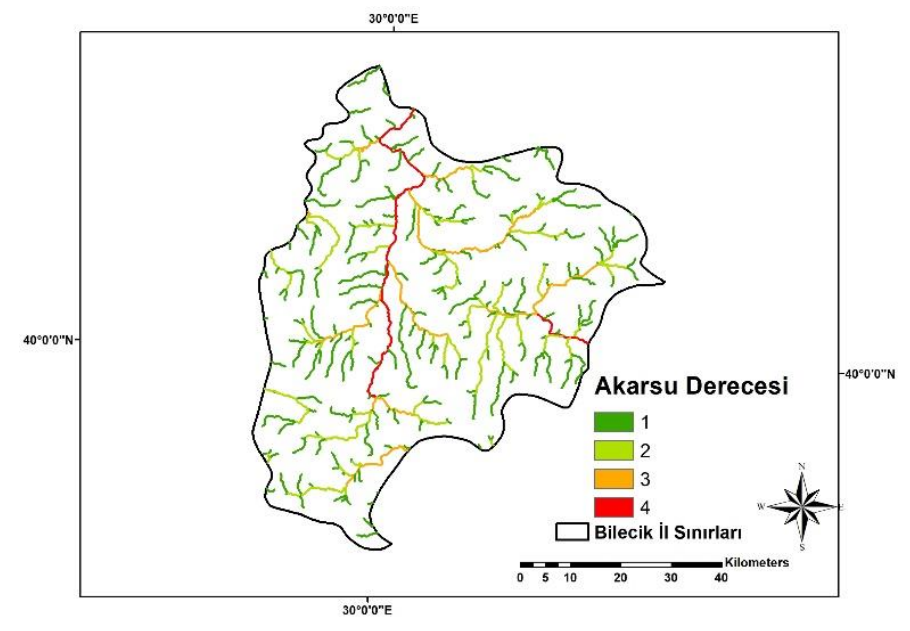

Şekil 8. Bilecik ili akarsu derecesi haritası

\section{B. Yöntem}

Taşkın risk haritalarının oluşturulması için bu çalışmada Analitik Hiyerarşi Süreci-Analytic Hierarchy Process (AHP) yönteminde en çok kullanılan çok kriterli karar verme analizi kullanılmıştır [21, 22]. Çok kriterli karar verme analizinde modelin kurulmasında yapılacak ilk adım taşkına etkisi olan faktörlerin belirlenmesidir. Literatürde birçok çalışmada taşkınlara etki eden faktörler göz önünde bulundurularak, bu çalışmada yağgş̧, eğim, yükseklik, arazi kullanımı, akarsulara uzaklık gibi parametreler kullanılarak ağırlıklar belirlenmiştir [23-25]. Çalışmada Bilecik il sınırları için her bir parametrenin sınıf aralıkları önem derecelerine göre Tablo 2'de verilmiştir.

Tablo 2. Yöntemde kullanılan faktörlere atanan ağırlık değerleri

\begin{tabular}{|c|c|c|c|c|}
\hline Taşkına Etki Eden Faktörler & Etki Yüzdesi (\%) & \multicolumn{2}{|c|}{ Sinıf Aralıkları } & Ăğırlık Değeri \\
\hline \multirow{4}{*}{ Yağgş (mm) } & \multirow{4}{*}{20} & \multicolumn{2}{|c|}{$432,11-450$} & 1 \\
\hline & & \multicolumn{2}{|c|}{$450-470$} & 2 \\
\hline & & \multicolumn{2}{|c|}{$470-490$} & 3 \\
\hline & & \multicolumn{2}{|c|}{$490-505,39$} & 4 \\
\hline \multirow{4}{*}{ Eğim $\left(^{\circ}\right)$} & \multirow{4}{*}{15} & \multicolumn{2}{|c|}{$0-15$} & 4 \\
\hline & & \multicolumn{2}{|c|}{$15-30$} & 3 \\
\hline & & \multicolumn{2}{|c|}{$30-45$} & 2 \\
\hline & & \multicolumn{2}{|c|}{$>45$} & 1 \\
\hline \multirow{4}{*}{ Yükseklik (m) } & \multirow{4}{*}{10} & \multicolumn{2}{|c|}{$80-500$} & 4 \\
\hline & & \multicolumn{2}{|c|}{$500-1000$} & 3 \\
\hline & & \multicolumn{2}{|c|}{$1000-1500$} & 2 \\
\hline & & \multicolumn{2}{|c|}{$>1500$} & 1 \\
\hline \multirow{4}{*}{ Arazi Kullanımı } & \multirow{4}{*}{25} & \multicolumn{2}{|c|}{ Yapay Yüzeyler } & 4 \\
\hline & & \multicolumn{2}{|c|}{ Tarım Alanları } & 3 \\
\hline & & \multicolumn{2}{|c|}{ Orman Alanları } & 2 \\
\hline & & \multicolumn{2}{|c|}{ Su Yüzeyleri } & 1 \\
\hline \multirow{16}{*}{ Akarsulara Uzaklık (m) } & \multirow{4}{*}{4} & \multirow{4}{*}{ 1.Derece } & $0-25$ & 4 \\
\hline & & & $25-50$ & 3 \\
\hline & & & $50-75$ & 2 \\
\hline & & & $75-100$ & 1 \\
\hline & \multirow{4}{*}{6} & \multirow{4}{*}{ 2.Derece } & $0-25$ & 4 \\
\hline & & & $25-50$ & 3 \\
\hline & & & $50-75$ & 2 \\
\hline & & & $75-100$ & 1 \\
\hline & & & $0-25$ & 4 \\
\hline & & & $25-50$ & 3 \\
\hline & 8 & 3.Derece & $50-75$ & 2 \\
\hline & & & $75-100$ & 1 \\
\hline & & & $0-25$ & 4 \\
\hline & & & $25-50$ & 3 \\
\hline & 12 & 4.Derece & $50-75$ & 2 \\
\hline & & & $75-100$ & 1 \\
\hline
\end{tabular}




\section{SONUÇLAR}

Yağış, eğim, yükseklik, arazi kullanımı ve akarsulara uzaklık gibi parametrelerin ArcGIS 10.5 yazılımında raster formatında çok kriterli karar verme analizi yöntemi kullanılarak Bilecik ili için taşkın risk haritaları oluşturulmuştur. Analiz sonucunda 2000 yılı ve 2018 yılları için oluşturulan taşkın risk haritaları ve risk değişimini ortaya koyan grafikler Şekil 9'daverilmiştir.
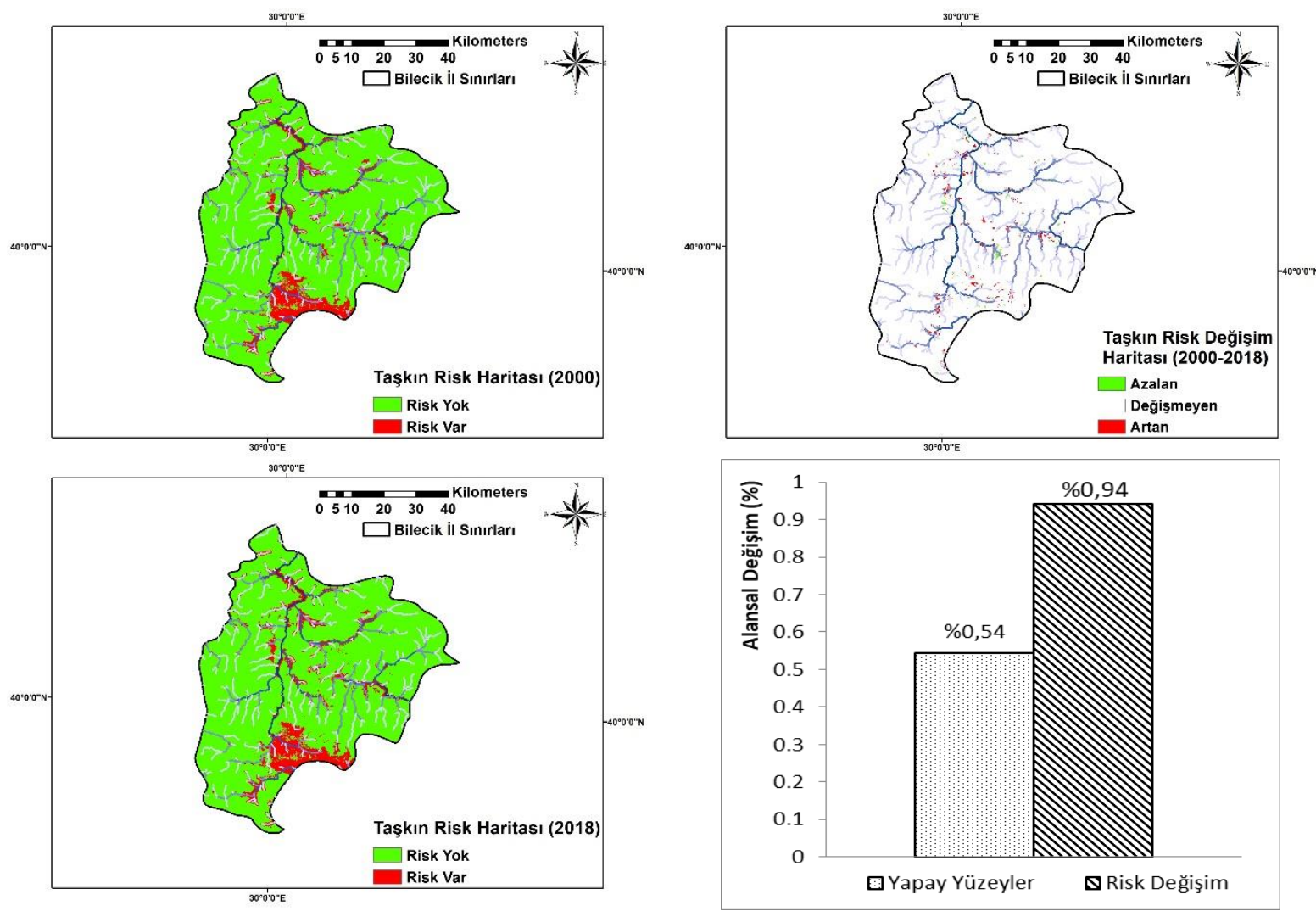

Şekil 9. Bilecik ili 2000 ve 2018 yıllarına ait taşkın risk haritaları

Çok kriterli karar verme analizinde kullanılan her bir parametre 4 sınıfta verildiğinden (Tablo 2.) sonuç risk haritasında anlamlı sonuçların "risk yok" ve "risk var" adı altında iki sınıfta incelenmesi uygun görülmüştür. $\mathrm{Bu}$ yöntemin farklı çalışma alanlarında farklı sınıflandırılmalarla değerlendirilebilmesi mümkündür. Ancak Bilecik ili için taşkın riskindeki değişimin en uygun gözlenebildiği sınıflandırma "risk yok" ve risk var" şeklinde iki sınıfta olduğu görülmüştür. Taşkın risk haritaları incelendiğinde ilk göze çarpan ilin güneyinde bulunan Bozüyük ilçesinin sürekli taşkın riski altında olduğudur. Bozüyük, yüksek yağış ortalaması, düşüm eğim ve kotları, merkezinden geçen akarsularıyla taşkın riskinin sürekli olarak var olduğu ortadadır. İl genelinde ise 2000 yılı ile 2018 yılları arasında yapay yüzeylerin (şehirleşme) \%0,54 artış gösterdiği bununla birlikte taşkın riskinin de \%0,94 artış gösterdiği görülmüştür. Yapılan analizler sonucu taşkın riskinin kentleşmedeki artıştan daha fazla artış gösterdiği ortaya çıkmıştır. Bu durumun Şekil 6'da görülen arazi değişimlerinde orman alanların yerini tarım arazilerine bırakması sonucu olduğu düşünülmektedir. Tarım arazileri orman alanlara göre taşkın riskinin daha fazla olduğu alanlardır. Ayrıca bölge mermer yatakları açısından zengin bir bölge olduğundan orman arazilerinin büyük bir bölümü yıllar içerisinde mermer ocakları olarak işletilmeye başlanmıştır. 


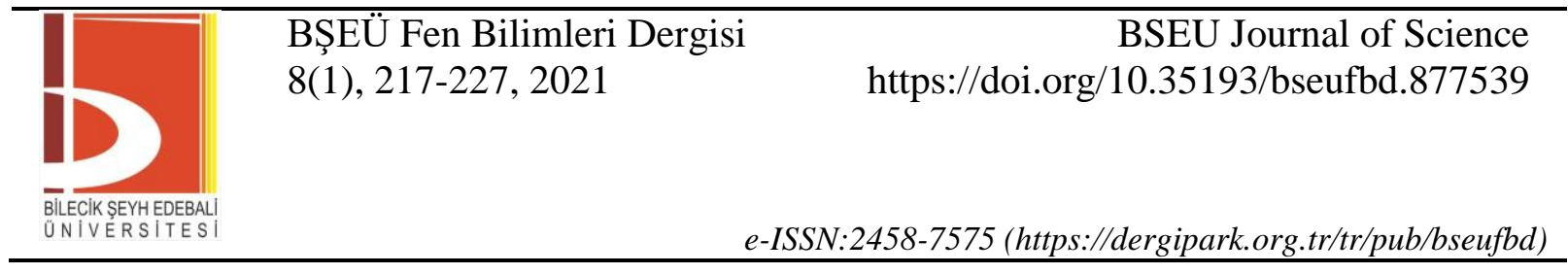

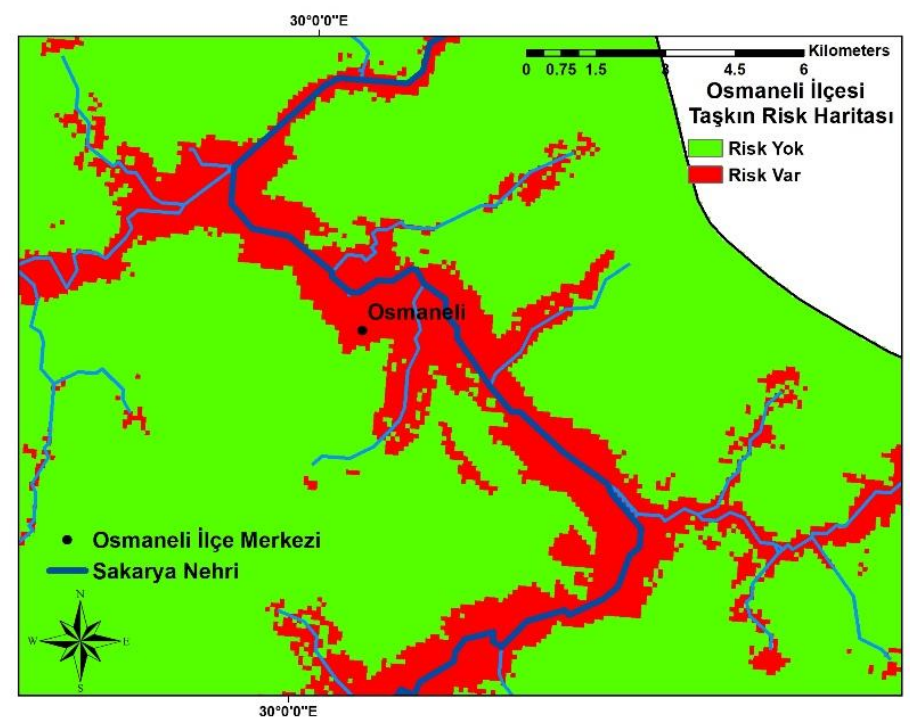

Şekil 10. Osmaneli ilçesi taşkın risk haritası

Bozüyük dışında riskli ilçelerden biri olan Osmaneli ilçesi olarak göze çarpmaktadır. Osmaneli Sakarya Nehri'nin kenarında olmasıyla taşkın riski altında olan bir bölgedir. Şekil 10'da verilen taşkın risk haritasında akarsu yataklarında taşkın riski altında olan bölgeler kırmızı renkte gözükmektedir. Tarım ve Orman Bakanlığı'nın 2018 yılında hazırladıkları Sakarya Havzası Taşkın Yönetim Planı'na göre Osmaneli ilçesi taşkının etki şiddeti ve yenilenme aralığına göre yüksek riskli bölgeler arasında gösterilmiştir [26].

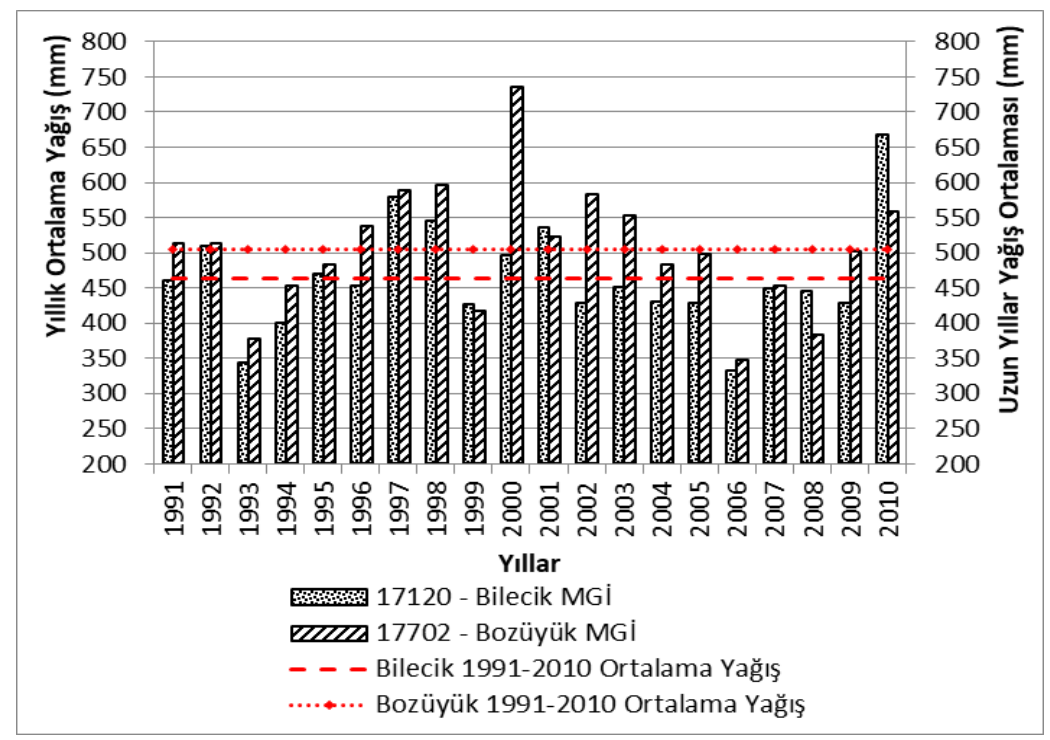

Şekil 11. Bilecik ve Bozüyük yağışölçer istasyonların yıllık ortalama yağış değerleri

Şehirleşmedeki değişimin yanı sıra yağışların yıllar içerisindeki değişimi de taşkın risk alanları üzerinde önemli etkileri vardır. Bu nedenle Şekil 11'de en çok ölçüm yapılan iki istasyonun yıllık yağış değişimleri verilmiştir. Şekil 11 incelendiğinde 17120 numaralı Bilecik yağışölçer istasyonunda, 1991-2010 yılları arasında $464,38 \mathrm{~mm}$ olan ortalama yağışın üzerinde gelen yağış yıl sayısının 7 olduğu görülmektedir. 17702 numaralı Bozüyük yağışölçer istasyonunda ise $505,35 \mathrm{~mm}$ olan uzun yıllar ortalamasının üzerinde gelen yağış yıl sayısı 10 'dur. İki önemli istasyondan alınan veriler göstermektedir ki taşkınların yaşanabileceği ortalama yağışların üzerinde gelen yağışlı yıl sayısı oldukça fazladır. Bu durum bölgede risk altında olan alanların planlı kentleşme ve taşkın kontrol yapılarıyla korunması gerekliliğini ortaya koymaktadır. 


\section{DEĞERLENDİRME VE ÖNERILER}

Bu çalışmada Bilecik ilinin 2000 yılından 2018 yılına kadarki arazi kullanım değişiminde orman alanlarının azalması, yapay yüzeylerin ve tarım alanlarının artışı il genelinde taşkın riskinde artışa neden olduğu görülmüş̧ür. Çalışmanın kapsamı sadece yıllık yağış ortalamalarının dağılımı ve arazi değişimi üzerine dayanmaktadır. Bu çalışmaya ek olarak ani taşkınların ve taşkın büyüklüklerinin hesaplanması da uzaktan algılama ve CBS destekli yapılması önerilebilir [13]. Ayrıca iklim değişikliği nedeniyle yağış rejimlerinin değişkenlik göstermesi yine taşkın riskini etkileyen önemli faktörlerdendir [27-29]. Bu çalışmada bulunan sonuçlar Bilecik ve Bozüyük gibi iki önemli istasyonun yağış verilerinin yıllık yağış dağılımlarının incelenmesiyle taşkın riski üzerindeki etkileri ortaya konmuştur. Özellikle yüksek yağış ortalamasıyla Bozüyük ilçesi taşkın riski altında olan bölge olarak dikkat çekmiş̧ir. Ayrıca bölgenin en büyük akarsuyu olan Sakarya Nehri'nin geçtiği Osmaneli ilçesi taşkın riski altında olan önemli bölgelerden birisidir. Akarsu yataklarına yakın, şehirleşme ve yağış ortalamasının fazla oluğu yerler taşkın riskinin fazla olduğu yerlerdir. Bu bölgelerde nüfus artışılla birlikte plansız ve çarpık kentleşme, yok edilen orman alanları, dere yataklarındaki yapılaşma taşkın felaketinin yaşatabileceği zararları da arttırması kaçınılmazdır. Bu tarz çalışmalarla yapılan taşkın risk değerlendirmelerinin yerel yönetimlerle taşkın felaketlerinin önüne geçilmesi için birlikte ele alınması gerektiği önerilmektedir. Sonuç olarak, bu tarz çalışmaların ülkemizin sosyal ve ekonomik olarak taşkın felaketinden daha az etkilenmesi için literatüre bir katkı vereceği öngörülmektedir

\section{TEŞEKKÜR}

Çalışmada kullanılan verilerin temininde yardımcı olan Devlet Su İşleri 3. Bölge Müdürlüğü ve Meteoroloji İşleri Genel Müdürlüğü başta olmak üzere tüm diğer kurumlara katkılarından dolay1 teşekkür ederiz.

\section{KAYNAKLAR}

[1] Atay, H., Tuvan, A., Demir, O. \& Balta, I. (2012).İklim değişikliğinin sağlık üzerine etkileri. T.C. Orman ve Su İşleri Bakanlığı, Meteoroloji Genel Müdürlüğü, Ankara.

[2] T.C. Orman ve Su İşleri Bakanlı̆̆ı. (2017). Taşkın Yönetimi. Su Yönetimi Genel Müdürlüğü, Ankara.

[3] Park, K. \& Lee, M. H. (2019). The Development and Application of the Urban Flood Risk Assessment Model for Reflecing upon Urban Planning Elements. Water, MDPI, 11, 1-17.

[4] Shanableh, A., Al-Ruzouq, R., Yılmaz, A. G., Siddique, M., Merabtene, T. \& Imteaz, M. A. (2018). Effects of Land Cover Change on Urban Floods and Rainwater Harvesting: A Case Study in Sharjah, UAE. Water, MDPI, 10(631), 1-17.

[5] Barasa, B. N. \& Perera, E. D. P. (2018). Analysis of land use change impacts on flash flood occurrences in the Sosiani River basin Kenya. International Journal of River Basin Management, 16(2), 179-188.

[6] Du, J., Zhang, Q., Yang, Y. \& Xu, W. (2019). Different Flooding Behaviors Due to Varied Urbanization Levels within River Basin: A Case Study from the Xiang River Basin, China. International Journal of Disaster Risk Science, 10(1), 89-102.

[7] Veerbeek, W. (2017). Estimating the impacts of urban growth on future flood risk a comparative study. Doctoral Thesis, Delft University of Technology, Netherlands.

[8] Haas, J. (2016). Remote Sensing of Urbanization and Environmental Impacts. Doctoral Thesis in Geoinformatics, KTH Architecture and the Built Environment, KTH Royal Institute of Technology, Sweden.

[9] Özkan, S. P. \& Tarhan, Ç. (2016). Detection of Flood Hazard in Urban Areas Using GIS: İzmir Case. Procedia Technology, 22, 373-381.

[10] Meng, X., Zhang, M., Wen, J., Du, S., Xu, H., Wang, L. \& Yang, Y. (2019). A Simple GIS-Based Model for Urban Rainstorm Inundation Simulation. Sustainability, 11(10), 1-19.

[11] Chen, J., Hill, A. A. \& Urbano, L. D. (2009). A GIS-based model for urban flood inundation. Journal of Hydrology, 373(1), 184-192.

[12] Lin, L. \& Liang, Q. (2019). Urban flood susceptibility analysis using a GIS-based multi-criteria analysis framework. Natural Hazards, 97, 455-475.

[13] Bayazıt, Y., Koç, C. \& Bakış, R. (2020). Urbanization impacts on flash urban floods in Bodrum Province, Turkey. Hydrological Sciences Journal, 66(6), 1-16.

[14] Uslu, G., Sesli, F. A. \& Uzun, B. (2018). Coğrafi Bilgi Sistemleri ile Taşkın Tehlike Haritalarının Belirlenmesi. Kent Akademisi, 11(4), 545-558.

[15] Bayazıt, Y., Bakış, R., Koç, C., Kaya, T. \& Özdemir, N. (2019). Formation of Eskişehir Province Flood Maps with Using of Geographical Information Systems. Journal of Geoscience and Environment Protection, 7, 151-159. 
[16] Jing, M. \& Wu, J. (2013).Fast image interpolation using directional inverse distance weighting for real-time applications. Optics Communications, 286, 111-116.

[17] Chen, F. W. \& Liu, C. W. (2012).Estimation of the spatial rainfall distribution using inverse distance weighting (IDW) in the middle of Taiwan. Paddy Water Environ. 10, 209-222.

[18] Liu, Z. N., Yu, X. Y., Jia, L. F., Wang, Y. S., Song, Y. C. \& Meng, H. D. (2021). The influence of distance weight on the inverse distance weighted method for ore-grade estimation. Scientific Reports, 11 (2689).

[19] Dou, X., Song, J., Wang, L., Tang, B., Xu, S., Kong, F. \& Jiang, X. (2018). Flood risk assessment and mapping based on a modified multi-parameter flood hazard index model in the Guanzhong Urban Area, China. Stochastic Environmental Research and Risk Assessment, 32, 1131-1146.

[20] CORINE (2020). Land Cover. Copernicus Land Monitoring Service, https://land.copernicus.eu/paneuropean/corine-land-cover, (28.01.2021).

[21] Saaty, T. I. (1990). How to make a decision: the analytic hierarchy process. European Journal of Operational Research, 48, 9-26.

[22] Saaty, T. I. (1990). An exposition of the ahp in reply to the paper remarks on the analytic hierarchy process. Management Science, 36(3), 259-268.

[23] Wang, Y., Li, Z., Tang, Z. \& Zeng, G. (2011). A GIS-Based Spatial Multi-Criteria Approach for Flood Risk Assessment in the Dongting Lake Region, Hunan, Central China. Water Resources Management, 25, 3465 3484.

[24] Zerger, A. (2002). Examining GIS decision utility for natural hazard risk modelling. Environmental Modelling \& Software, 17(3), 287-294.

[25] Kazakis, N., Kougias, I., \& Patsialis, T. (2015). Assessment offlood hazard areas at a regional scale using an index-basedapproach and Analytical Hierarchy Process: Application inRhodope-Evros region Greece. Science of the Total Environment, 538, 555-563.

[26] T.C. Tarım ve Orman Bakanlığı. (2018). Sakarya Havzası Taşkın Yönetim Planı. Su Yönetimi Genel Müdürlüğü, Ankara.

[27] Tabari, H. (2020).Climate change impact on flood and extreme precipitation increases with water availability. Scientific Reports, 10 (13768).

[28] Guhathakurta, P., Sreejith, O. P. \& Menon, P. A. (2011). Impact of climate change on extreme rainfall events and flood risk in India. Journal of Earth System Science, 120 (359).

[29] Schmitt, T. G. \& Scheid, C. (2020). Evaluation and communication of pluvial flood risks in urban areas. WIRE's Water, 7 (1). 